\title{
Poly(vinylidene fluoride) and copolymers as porous membranes for tissue engineering applications
}

\author{
J. Nunes-Pereira a, S. Ribeiro a, C. Ribeiro ${ }^{\text {a, }{ }^{* *}, \text { C.J. Gombek }}{ }^{\text {b }}$, F.M. Gama ${ }^{\text {c }}$, \\ A.C. Gomes ${ }^{\mathrm{d}}$, D.A. Patterson ${ }^{\mathrm{b}}$, S. Lanceros-Méndez ${ }^{\text {a, }}{ }^{*}$ \\ a Centro/Departamento de Física, Universidade do Minho, 4710-057 Braga, Portugal \\ ${ }^{\mathrm{b}}$ Bath Process Intensification Laboratory, Department of Chemical Engineering and Centre for Sustainable Chemical Technologies, \\ University of Bath, Claverton Down, Bath, BA2 7AY, United Kingdom \\ ${ }^{\mathrm{C}}$ IBB - Institute for Biotechnology and Bioengineering, Centre of Biological Engineering, Universidade do Minho, Campus de Gualtar, \\ 4710-057 Braga, Portugal \\ d CBMA (Centre of Molecular and Environmental Biology), Department of Biology, University of Minho, Campus of Gualtar, $4710-057$ \\ Braga, Portugal
}

\section{A R T I C L E I N F O}

\section{Article history:}

Received 30 March 2015

Accepted 1 May 2015

Available online 13 May 2015

\section{Keywords:}

Porous membranes

Poly(vinylidene fluoride)

Poly(vinylidene fluoride-co-

trifluoroethylene)

Poly(vinylidene fluoride-co-

hexafluoropropene)

Tissue engineering

\begin{abstract}
A B S T R A C T
Poly(vinylidene fluoride) (PVDF) and its main copolymers - poly(vinylidene fluoride-cohexafluoropropene), P(VDF-HFP), and poly(vinylidene fluoride-co-trifluoroethylene), $\mathrm{P}(\mathrm{VDF}-\mathrm{TrFE})$ - were processed by solvent casting at room temperature in the form of porous membranes. Copolymer membranes showed higher degree of porosity than PVDF, the average pore size being larger for P(VDF-TrFE) than for P(VDF-HFP) and PVDF. All membranes show high hydrophobicity with water contact angles in the range $94^{\circ}$ to $115^{\circ}$, and electroactive beta phase contents above 90\%. The adhesion and proliferation of both C2C12 myoblast and MC3T3-E1 pre-osteoblast cells on the membranes were investigated. It is demonstrated that PVDF membranes promote higher cell proliferation while P(VDFHFP) membranes show the lowest proliferation for both kinds of cell. The proliferation on P(VDF-TrFE) membranes is cell dependent, higher for MC3T3-E1 cells but lower for $\mathrm{C} 2 \mathrm{C} 12$ cells, related to the effect of the highly porous structure on the preferred morphology of each cell type, as the higher pore size and porosity of the P(VDF-TrFE) membrane induce cell elongation, which is preferred just by the $\mathrm{C} 2 \mathrm{C} 12$ muscle cells.
\end{abstract}

(c) 2015 Elsevier Ltd. All rights reserved.

\section{Introduction}

Tissue engineering (TE) is continuously evolving as an exciting and multidisciplinary field aiming to develop biological substitutes to restore, replace or regenerate defective tissues [1]. Successful tissue engineering generally relies on two essential elements: cells and scaffolds, scaffold design being, therefore, a key aspect of TE.

\footnotetext{
* Corresponding author. Tel.: +351 253604320; fax: +351 253604061.

** Corresponding author.

E-mail addresses: cribeiro@fisica.uminho.pt (C. Ribeiro), lanceros@ fisica.uminho.pt (S. Lanceros-Méndez).
}

Scaffolds are primarily designed to support cell colonization and formation of tissue, mimicking the tissue extracellular matrix [2]. Scaffolds for TE should meet several design criteria with respect to geometry, microstructure and physicochemical properties. The scaffold should be designed according to the structure of the tissue into which it is to be implanted [3]. An ideal scaffold should be: (i) biocompatible; (ii) bear the proper shape; (iii) appropriate mechanical strength depending on the desired application; and (iv) an extensive network of interconnected pores for cell grow and proliferation [4]. Synthetic polymers are more frequently considered in the preparation of polymer scaffolds, as their properties can 
be finely tuned for the desired application [4,5]. These scaffolds are typically required to be biodegradable for medical implants or related applications [6] but not necessarily so for cell culture studies, expansion or differentiation prior to medical use of the cells $[7,8]$.

Within this approach, quasi-two dimensional membranes can also play an important role in manipulating cell functions and, depending on the type of cells and the specific application, quasi-two dimensional membranes are even required $[9,10]$. Pore size, pore interconnectivity and total porosity are essential features of these membranes, pore size influencing cell adhesion in vitro and ability to colonize the scaffold [11], also affecting cell morphology and phenotypic expression [12]. In this way, biocompatible but not necessarily biodegradable quasitwo dimensional membranes are used for specific cell proliferation and differentiation studies or before medical implantation [8].

Biomedical applications based on fluorinated polymers have recently attracted much interest due to their unique properties, including high dielectric constant, chemical resistance, lubricity, sizing tolerance for device fabrication and biocompatibility. Poly(vinylidene fluoride) (PVDF) and its copolymers have been further recognized as important and unique materials for biomedical applications due to their high electroactive response, showing the highest piezo, pyro and ferroelectric responses among polymeric materials. In particular, piezoelectricity, the ability to convert mechanical signals into electrical ones and viceversa, allows the development of smart scaffolds to stimulate cell growth and differentiation of specific tissues undergoing electro-mechanical stimuli in their function, such as bone and muscle tissues, as well as the fabrication of devices such as biosensors and mechanical sensors and actuators $[13,14]$.

PVDF is a semi-crystalline polymer and exhibits five distinct crystalline phases: $\alpha, \beta, \delta, \gamma$ and $\varepsilon$. The $\beta$-phase (Fig. 1 ) is the one with the largest interest for technological applications due to its electroactive properties: piezoelectric, pyroelectric and ferroelectric. This phase is obtained with a porous microstructure directly by solution casting with solvent evaporation and crystallization temperatures below $70^{\circ} \mathrm{C}$. Two of the most relevant co-polymers of PVDF are poly(vinylidene fluoride-co-trifluoroethylene) (P(VDFTrFE)) and poly(vinylidene fluoride-co-hexafluoropropene) (P(VDF-HFP)) (Fig. 1) [14]. P(VDF-TrFE) shows a Curie temperature $\left(T_{c}\right)$ below melting temperature $\left(T_{m}\right)$ and crystallizes in the ferroelectric $\beta$-phase regardless of

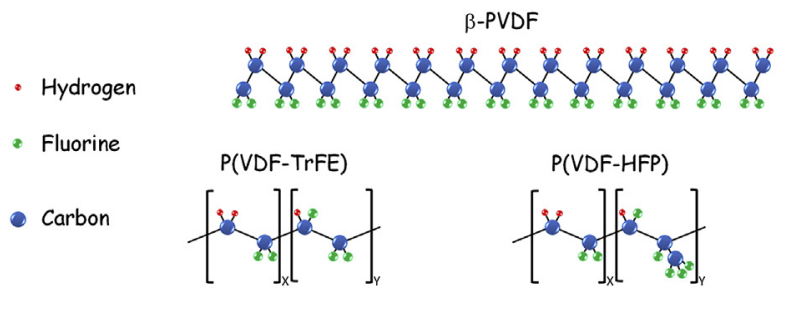

Fig. 1. Schematic representation of the $\beta$-PVDF chain conformation and the $\mathrm{P}(\mathrm{VDF}-\mathrm{TrFE})$ and $\mathrm{P}(\mathrm{VDF}-\mathrm{HFP})$ repeat units. processing technique, melt or solution casting, for VDF contents between 50 and $80 \%$. P(VDF-HFP) (Fig. 1) is also a semi-crystalline polymer with lower degree crystallinity than PVDF and with strong ferroelectric properties when samples are prepared by solvent casting [14].

The main differences between the copolymers with respect to their piezoelectric properties are the following [14]: $\mathrm{d}_{31}(\mathrm{pC} / \mathrm{N})$ is between 8 and 22 for PVDF, 12 for P(VDFTrFE) and 30 for $\mathrm{P}(\mathrm{VDF}-\mathrm{HFP})$ and $\mathrm{d}_{33}(\mathrm{pC} / \mathrm{N})$ is between -24 and -34 for PVDF, -38 for P(VDF-TrFE) and -24 for P(VDFHFP).

PVDF $d_{33}$ and $d_{31}$ values are overall comparable with the ones observed for the copolymers, however PVDF presents generally higher degree of crystallinity, which results in higher electroactive $\beta$-phase content in the sample. Further, the surface morphology of polymer and copolymers are generally different in terms of spherulite size and organization [15].

As previously mentioned, cell-material interactions play critical roles in the success of scaffolds for tissue engineering, since chemical and physical cues of biomaterials regulate cell adhesion, migration, proliferation and differentiation [16]. Several tissues and cells are responsive to electrical fields and stimuli [17], such as bone [18], nerves [19] and cardiac and skeletal muscle [20,21].

Some studies have demonstrated the influence of pore size and degree of porosity of some membranes on cell proliferation for tissue engineering applications [22-24]. The optimal pore size of porous membranes for MC3T3 cell proliferation is still controversial [10,22,25]. To our knowledge there are no studies using PVDF and copolymers porous membranes for $\mathrm{C} 2 \mathrm{C} 12$ and MC3T3 cell proliferation studies despite the fact that the electroactive properties of these membranes are interesting for muscle and bone regeneration $[26,27]$. Due to the similar electroactive properties of the materials, the use of different copolymer will allow study of the influence of the different morphologies and surface energy of the material on cell response.

Therefore, this study is devoted to evaluate comparatively the suitability of PVDF, P(VDF-TrFE) and P(VDF-HFP)) membranes for tissue engineering applications by studying the adhesion and proliferation of both $\mathrm{C} 2 \mathrm{C} 12$ and MC3T3E1 cells. This study is relevant due to the aforementioned interest of piezoelectric polymer for tissue engineering applications and due to the differences of polymer and copolymers in terms of electroactivity, degree of crystallinity and microstructure, which certainly affect cell-material interactions.

\section{Experimental details}

\subsection{Materials}

Poly(vinilidene fluoride) (PVDF) Solef ${ }^{\circledR} 6020\left(\mathrm{M}_{\mathrm{w}}=\right.$ 670-700 kDa), poly(vinylidene fluoride trifluorethylene) ( $\mathrm{P}(\mathrm{VDF}-\mathrm{TrFE})$ ) (70/30) and poly(vinylidene fluoride-cohexafluropropylene) $\mathrm{P}(\mathrm{VDF}-\mathrm{HFP})$ Solef $^{\mathrm{B}} 21216\left(\mathrm{M}_{\mathrm{w}}=\right.$ 570-600 kDa) were acquired from Solvay; N,Ndimethylformamide (DMF) was obtained from Merck. 


\subsection{Membrane preparation}

PVDF, P(VDF-TrFE) and P(VDF-HFP) membranes were prepared by adding the polymer powder to DMF at a concentration of $15 / 85$ polymer/solvent $(w / w)$. The solutions were prepared at room temperature with the help of a magnetic stirrer until complete polymer dissolution, i.e., until a homogeneous and transparent solution was obtained. In order to prevent the formation of aggregates and to improve polymer dissolution, the solution temperature was increased $5{ }^{\circ} \mathrm{C}$ above room temperature during the first $15 \mathrm{~min}$. Then, the solutions were placed in a glass Petri dish and the DMF solvent evaporated at room temperature for 15 days in a gas extraction chamber. The thickness of the membranes obtained ranged between 100 and $300 \mu \mathrm{m}$.

\subsection{Membrane characterization}

Membranes were coated with a thin gold layer using a sputter coater (Polaron, model SC502) and the morphology analyzed using a scanning electron microscope (SEM) (650 Quanta FEI) with an accelerating voltage of $3 \mathrm{kV}$.

The porosity and pore size of the membranes was evaluated by $\mathrm{Hg}$ porosimetry on a Micrometrics Autopore III. A weighed amount of membrane was placed in the cup of the penetrometer (powder 3cc, 1.1cc intrusion) and mercury intrusion was measured over the pressure range (0 - 30000 psi).

Contact angle measurements (sessile drop in dynamic mode) were performed at room temperature in a Data Physics OCA20 device using ultrapure water (3 mL droplets) as test liquid. At least 3 measurements on each sample were performed in different sample locations and the average contact angle was calculated.

Polymer phase within the polymers was evaluated by Fourier Transformed Infrared Spectroscopy (FTIR) performed at room temperature with a Jasco FT/IR-4100. FTIR spectra were collected in the ATR mode from 4000 to $600 \mathrm{~cm}^{-1}$ after 32 scans with a resolution of $4 \mathrm{~cm}^{-1}$. The relative $\beta$-phase content of the membranes was calculated as described in [14]:

$\mathrm{F}(\beta)=\frac{\mathrm{A}_{\beta}}{\left(\mathrm{K}_{\beta} / \mathrm{K}_{\alpha}\right) \mathrm{A}_{\alpha}+\mathrm{A}_{\beta}}$

where $\mathrm{F}(\beta)$ is the $\beta$-phase content; $\mathrm{A}_{\alpha}$ and $\mathrm{A}_{\beta}$ the absorbance at 766 and $841 \mathrm{~cm}^{-1} ; \mathrm{K}_{\alpha}$ and $\mathrm{K}_{\beta}$ the absorption coefficients at respective wavenumber which values are $6.1 \times 10^{4}$ and $7.7 \times 10^{4} \mathrm{~cm}^{2} / \mathrm{mol}$, respectively.

The degree of crystallinity $\left(\chi_{c}\right)$ was calculated from the melting/crystallization enthalpy $\left(\Delta \mathrm{H}_{\mathrm{f}}\right)$ measured using a Differential Scanning Calorimetry (DSC). Scans between 25 and $200^{\circ} \mathrm{C}$, at a heating rate of $20^{\circ} \mathrm{C} \mathrm{min}^{-1}$ for both cooling and heating, were performed in a Perkin-Elmer DSC 8000 instrument under flowing nitrogen. All tests were performed in $30 \mu \mathrm{L}$ aluminum pans with perforated lids to allow the release and removal of decomposition products. The degree of crystallinity $\left(\chi_{c}\right)$ was calculated from the enthalpy of the melting peak $\left(\Delta \mathrm{H}_{\mathrm{f}}\right)$ based on the enthalpy of a $100 \%$ crystalline sample, through the following equation:
$\chi_{\mathrm{c}}=\frac{\Delta \mathrm{H}_{\mathrm{f}}}{\chi \Delta_{\alpha}+y \Delta H_{\beta}} \times 100$

where $x$ is the weight fraction of the $\alpha$-phase and $y$ is the weight fraction of $\beta$-phase determined from FITR measurements. $\Delta \mathrm{H}_{\alpha}$ is the melting enthalpy of pure crystalline $\alpha$-PVDF and $\Delta \mathrm{H}_{\beta}$ is the melting enthalpy of pure crystalline $\beta$-PVDF which are reported to be $93.04 \mathrm{~J} / \mathrm{g}$ and $103.4 \mathrm{~J} / \mathrm{g}$, respectively $[28,29]$.

\subsection{Cell culture and evaluation}

\subsubsection{Membrane sterilization}

For the in vitro assays, circular membranes were cut with diameter of $6 \mathrm{~mm}$. For sterilization, the samples were exposed to ultraviolet (UV) light for $2 \mathrm{~h}$ ( $1 \mathrm{~h}$ each side) and washed 5 times for 5 min with a sterile phosphate buffer saline (PBS) solution. Then, the samples were placed in 96well cell culture plates.

\subsubsection{Cell culture}

Two different cell lines were used: C2C12 myoblast and MC3T3-E1 pre-osteoblast. C2C12 and MC3T3-E1 cells were grown in $75 \mathrm{~cm}^{2}$ cell-culture flask and cultured in Dulbecco's Modified Eagle's Medium (DMEM, Gibco) containing 4.5 g.L $\mathrm{L}^{-1}$ and 1 g.L $\mathrm{L}^{-1}$, respectively, supplemented both with $10 \%$ Fetal Bovine Serum (FBS, Biochrom) and 1\% Penicillin-Streptomycin ( $\mathrm{P} / \mathrm{S}$, Biochrom). Flasks were incubated at $37{ }^{\circ} \mathrm{C}$ in humidified air containing $5 \% \mathrm{CO}_{2}$ atmosphere. The culture medium was changed every two days until confluence (60-70\%), when they were trypsinized with $0.05 \%$ trypsin-EDTA. Then, cell culture on the membranes was performed.

\subsubsection{Cell proliferation}

The cells were seeded in the membranes onto 96 well plates at a concentration of $2 \times 10^{4}$ and $3 \times 10^{4}$ cells. $\mathrm{mL}^{-1}$, for C2C12 and MC3T3-E1 cells, respectively. Controls were run at the same time and concentration in wells without material. Cell proliferation was evaluated after 1 and 2 days for C2C12 cells and after 1 and 3 days for MC3T3-E1 cells. These times were selected according to [30,31] in order to evaluate cell adhesion and the initial steps of the cell morphology variation on the different substrates. The [3(4,5-dimethylthiazol-2-yl)-5-(3-carboxymethoxyphenyl)2-(4sulfophenyl)-2H-tetrazolium, inner salt] (MTS, Promega) assay was carried out to determine the cell viability. At appropriate times, the culture medium was removed from the wells and the samples were washed with PBS. Thereafter, DMEM without phenol red and FBS were added to the MTS solution in 1:5 ratio and added to each well. After $3 \mathrm{~h}$ of incubation at $37{ }^{\circ} \mathrm{C}$ in a $5 \% \mathrm{CO}_{2}$ incubator, $100 \mu \mathrm{L}$ of each sample was transferred to another 96-well plate and the absorbance of each well was measured at $490 \mathrm{~nm}$ using a spectrophotometric plate reader (Biotech Synergy HT). All quantitative results were obtained from triplicate samples.

\subsubsection{Cell morphology}

Cytoskeletal morphology of the cells seeded on the various substrates was determined using scanning electron 
microscopy (SEM, Quanta 650 FEG). After each incubation time, the medium of each well was removed and the samples were washed with PBS and fixed with $4 \%$ formaldehyde (Sigma) in PBS for $10 \mathrm{~min}$ at $37^{\circ} \mathrm{C}$. The samples were again washed with PBS and dehydrated in a graded series of ethanol solutions $(10,30,50,60,70,80,90$ and $100 \%$ in water). Later, the samples were placed in vacuum at room temperature for $4 \mathrm{~h}$. The dried samples were then gold sputtered in vacuum and evaluated by SEM.

\section{Results and discussion}

\subsection{Membranes properties}

It has been shown that the preparation of PVDF, P(VDFTrFE) and P(VDF-HFP) membranes under varying solvent evaporation conditions gives rise to porous structures with controllable pore size and degree of porosity within specific limits [32-34].

Fig. 2 shows the cross section scanning electron microscopy (SEM) images of the polymer membranes prepared under the same conditions.

The cross section image of the PVDF membrane (Fig. 2a) shows the porous structure of the $\beta$-PVDF crystalline phase, where the characteristic polymer spherulites are slightly perceptible. The crystallization process at low temperature (room temperature) is determined by the binary polymer/ solvent phase diagram and based on the crystallization from stable nuclei [32]. Solvent evaporation and polymer crystallization lead to a porous microstructure with high degree of porosity and low spherulitic radius due to the reduced polymer chains at low temperature, avoiding the polymer occupying the free space left behind by the evaporated solvent [32]. The P(VDF-TrFE) membranes (Fig. 2b) show homogeneous porous structures as a result of the spinodal liquid-liquid phase separation. The crystallization process is different from that of PVDF due to the irregularity introduced by TrFE groups in the polymer chain, shifting the liquid-liquid binary region prior to crystallization [34]. Finally, P(VDF-HFP) (Fig. 2c) shows a morphology composed of macro- and micro-voids as a results of the liquid-liquid separation in the phase diagram. Low evaporation temperatures favor high degree of porosity, similar to what happens with PVDF membranes [35].

Fig. 3 shows the degree of porosity and average pore size of the membranes of polymer and co-polymers measured by $\mathrm{Hg}$ porosimetry.

Fig. 3a shows that copolymer membranes bear higher degree of porosity than PVDF, and also the most compact microstructure (Fig. 2a). P(VDF-TrFE) and P(VDF-HFP) show degrees of porosity higher than $70 \%$ while the PVDF membranes do not reach $30 \%$. Regarding pore size (Fig. $3 \mathrm{~b}$ ), $\mathrm{P}(\mathrm{VDF}-\mathrm{TrFE})$ membranes show the highest average pore size values, around $0.5 \mu \mathrm{m}$. On the other hand, the average pore size obtained for PVDF and P(VDF-HFP) is $\sim 0.1 \mu \mathrm{m}$ and is $\sim 0.3 \mu \mathrm{m}$, respectively. The degree of porosity and average pore size are in agreement with the values reported to membranes prepared by TIPS in similar systems, presenting high overall porosity and controllable pore size [36].

The surface water contact angle of the membranes was measured in order to evaluate their overall hydrophobicity, this being strongly influenced both by material characteristics and, in the case of porous membranes, microstructure
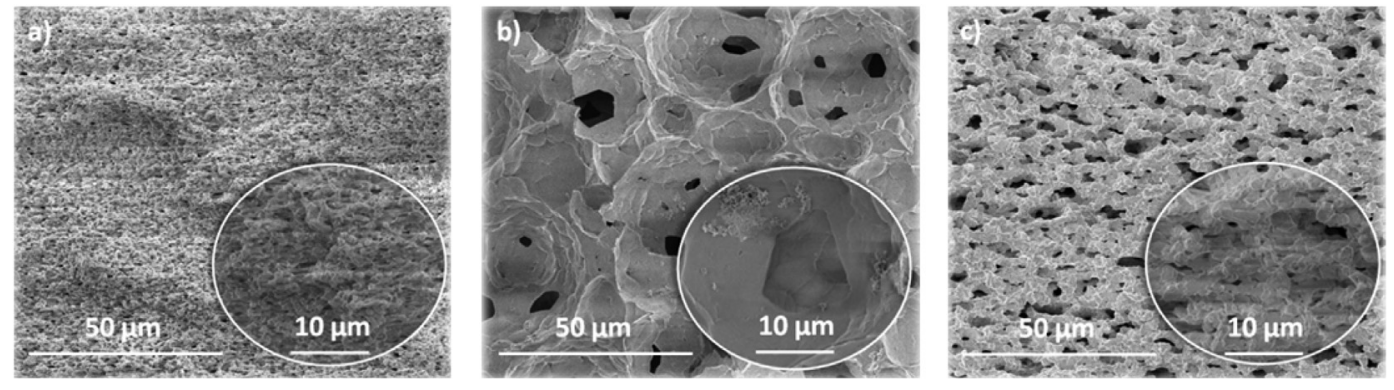

Fig. 2. Cross section pictures of: a) PVDF, b) P(VDF-TrFE) and c) P(VDF-HFP).
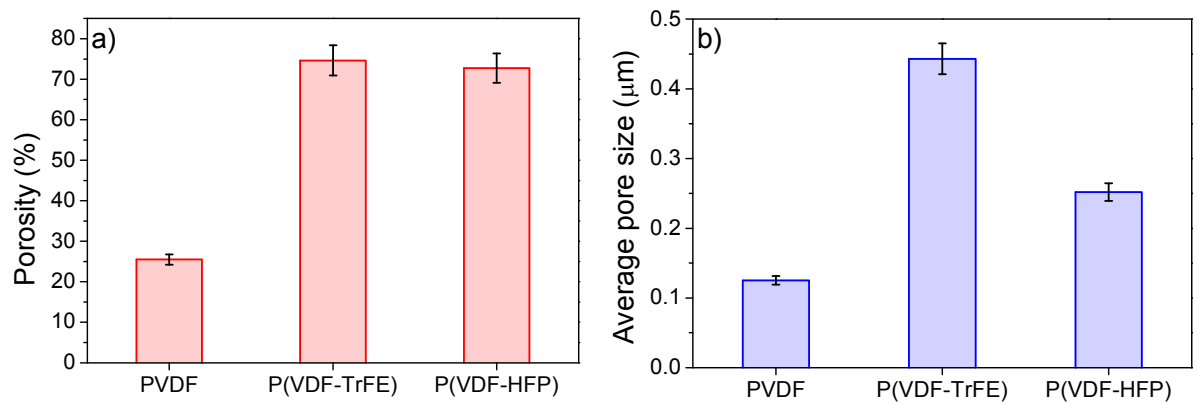

Fig. 3. Degree of porosity and average pore size of the polymer and co-polymer membranes. 

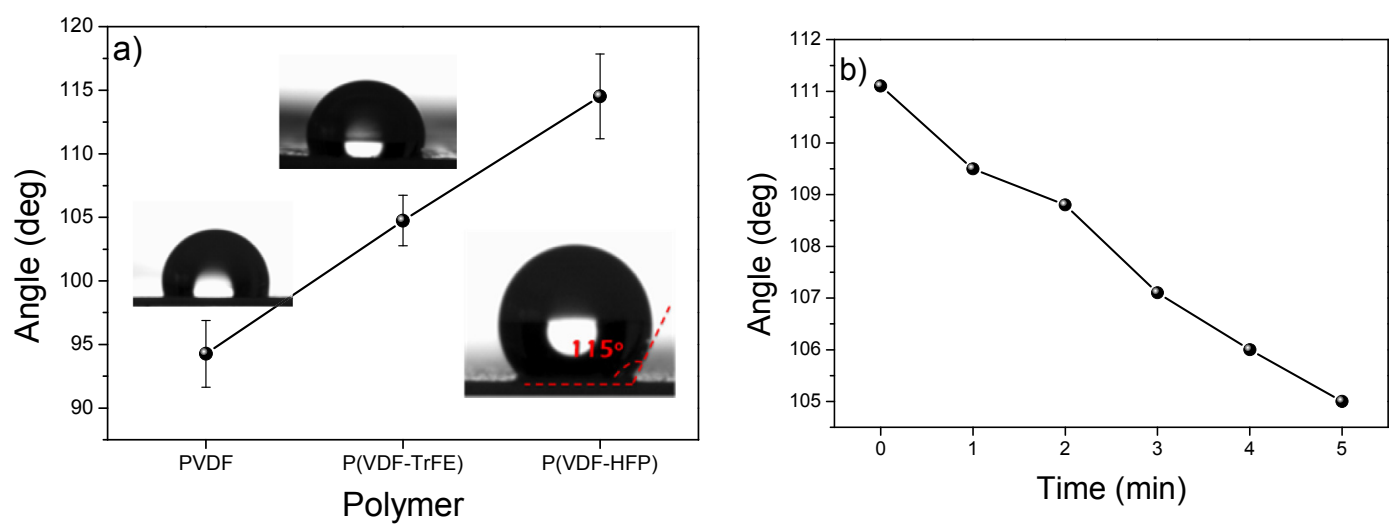

Fig. 4. a) Contact angle of PVDF, $\mathrm{P}(\mathrm{VDF}-\mathrm{TrFE})$ and $\mathrm{P}(\mathrm{VDF}-\mathrm{HFP})$ membranes; $\mathrm{b})$ Contact angle versus time for $\mathrm{P}(\mathrm{VDF}-\mathrm{HFP})$ membrane.

[31]. Fig. 4 shows the contact angle of the different polymeric membranes (Fig. 4a) and the dynamic contact angle of P(VDF-HFP) membrane (Fig. 4b).

All membranes show hydrophobic behavior. The PVDF membrane shows the lowest contact angle, around $94^{\circ}$, slightly higher than previous reports $\left(86-88^{\circ}\right)$ [37]. Copolymers membranes present higher contact angles than the pristine polymer, around 105 and $115^{\circ}$ for $\mathrm{P}(\mathrm{VDF}-$ TrFE) and P(VDF-HFP), respectively, which is mainly attributed to the presence of TrFE and HFP groups that increase the fluorine content in the membranes [38], which overcome the effect of the larger degree of porosity and pore size.

Fig. $4 \mathrm{~b}$ shows the dynamic contact angle for the P(VDFHFP) membrane, which decrease over time, indicating that water droplets spread after deposition, probably due to slight absorption within the membrane because of the porosity (Fig. 2c); the behavior shown is representative for all membranes.

Fig. 5 shows the FTIR spectra of the membranes.

The PVDF membranes crystallize preferentially in the polymer polar phase $(\sim 89 \%)$, as indicated by the presence of the $840 \mathrm{~cm}^{-1}$ characteristic band of $\beta$-phase PVDF [14]. The same occurs for the P(VDF-TrFE) membranes, as indicated by the presence of the characteristic vibration modes at 851,886 and $1402 \mathrm{~cm}^{-1}$ [39]. Finally, P(VDF-HFP) membrane also presents preferentially the vibration band at $840 \mathrm{~cm}^{-1}$, characteristic of the $\beta$-phase $(\sim 90 \%)$ [40]. Thus, room temperature solvent evaporation promotes the nucleation of the electroactive phase, as discussed in [14].

The degree of crystallinity calculated by equation 2 from the DSC scans (data not shown) is $55 \pm 3.0$ for PVDF, $28 \pm 1.4$ for P(VDF-TrFE) and $35 \pm 1.8$ for P(VDF-HFP).

The values of the degree of crystallinity are in agreement with the literature [14]. The pure polymer PVDF shows the highest value (55\%), followed by HFP and the TrFE copolymers with 35 and $28 \%$, respectively. Thus, though all the samples show a similar $\beta$-phase content within the crystalline fraction, PVDF has a higher degree of crystallinity and, therefore, shows a larger amount of electroactive $\beta$-phase in the overall sample.

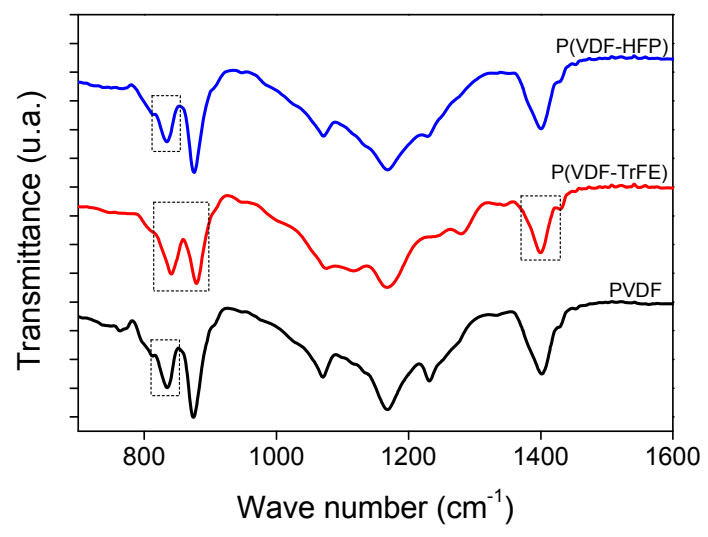

Fig. 5. FTIR spectra of the PVDF, $\mathrm{P}(\mathrm{VDF}-\mathrm{TrFE})$ and $\mathrm{P}(\mathrm{VDF}-\mathrm{HFP})$ membranes.

\subsection{Cell proliferation and morphology}

Both cell types, C2C12 myoblast and MC3T3-E1 osteoblasts, were used in previous studies to analyze the cell proliferation on $\beta$-PVDF films (non-poled and poled). It was verified that $\mathrm{C} 2 \mathrm{C} 12$ cell proliferation after 2 days is higher when these cells are seeded on $\beta$-PVDF "poled" compared to the other PVDF films [31]. The polarization effect was also studied for MC3T3-E1 cell proliferation and it was observed that positively charged $\beta$-PVDF films promote higher osteoblast proliferation $[30,41]$. So, depending on the cell type, the different polarization states may influence differently the cell proliferation, highlighting the relevance of the surface charge. In the same way, another important parameter that can affect the cell adhesion and proliferation is the scaffold design. Therefore, porous membranes are studied for the construction of scaffolds for tissue engineering applications, namely bone [11].

In order to determine the suitability of the membranes for tissue engineering and biomedical applications, the cell viability (Fig. 6) and morphology (Fig. 7) of cells grown on the different membranes was assessed using MTS and SEM assay, respectively. 

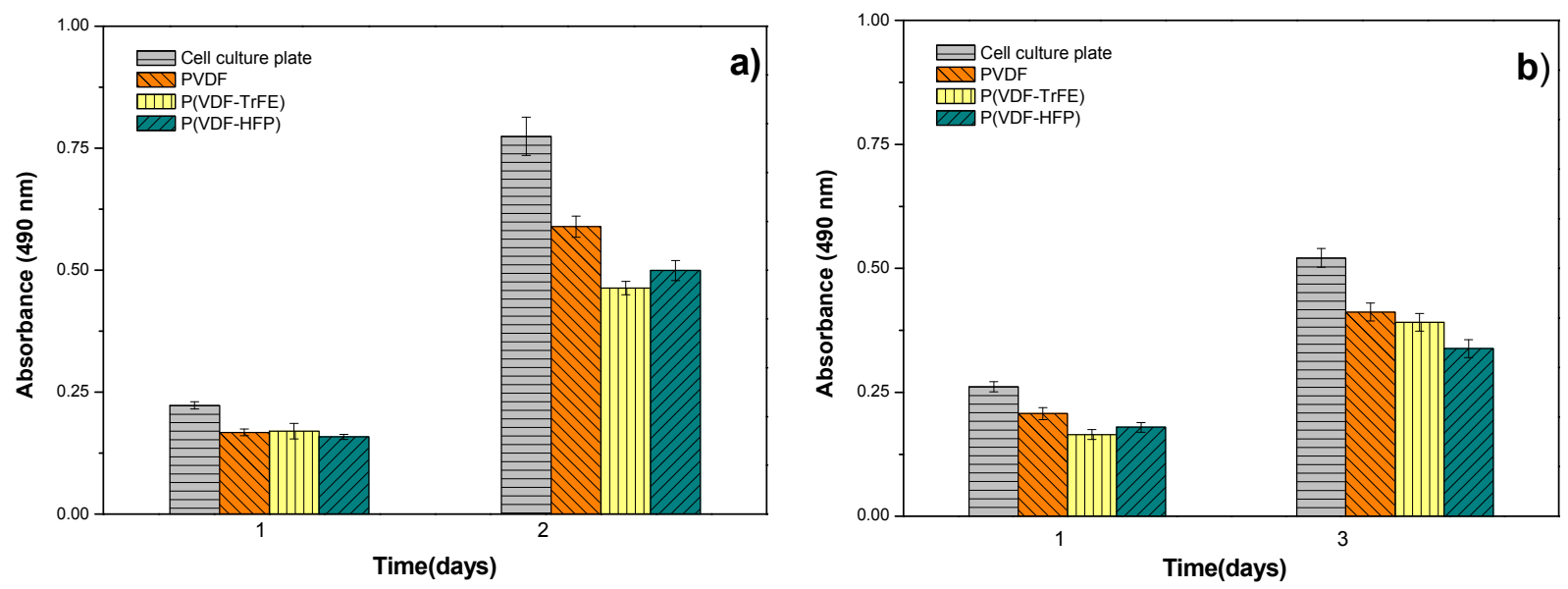

Fig. 6. Cell viability of different cells growing on porous membranes of PVDF and copolymers as measured by MTS assay: a) C2C12 cells up to 2 days of culture and b) MC3T3-E1cells up to 3 days of culture.
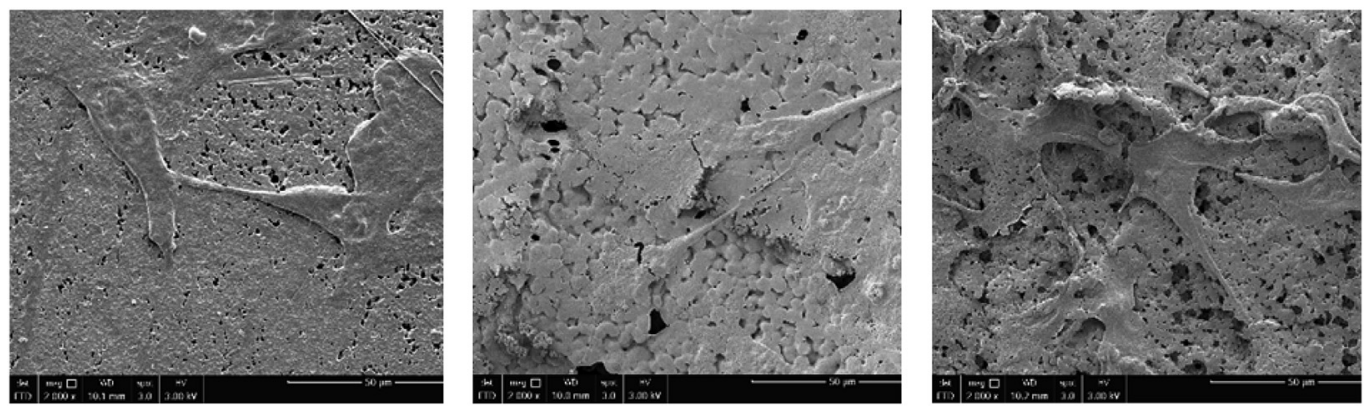

Fig. 7. Cell morphology of $\mathrm{C} 2 \mathrm{C} 12$ myoblasts seeded on different porous membranes after 1 day of culture (left) PVDF, (middle) P(VDF-TrFE) and (right) P(VDFHFP) obtained by SEM. The scale bar is $50 \mu \mathrm{m}$ for all samples.

Fig. 6a shows that, after 1 culture day of $\mathrm{C} 2 \mathrm{C} 12$ cells, control and samples present similar cell density, suggesting that the adhesion in the different materials is comparable to that observed on the culture plate. However, after 2 days, the $\mathrm{C} 2 \mathrm{C} 12$ proliferation on the membranes shows lower proliferation than the control. Among the membranes, PVDF support the $\mathrm{C} 2 \mathrm{C} 12$ myoblast proliferation slightly better.

The MC3T3-E1 cells also proliferated on PVDF and copolymer membranes, as demonstrated in Fig. 6b, although to lower extent than $\mathrm{C} 2 \mathrm{C} 12$, and significantly less than in the polystyrene culture plates.

The optimal pore size for osteoblast activity is still controversial, as an optimal value in which they grow better is yet to be defined [10]. In the present study, MC3T3-E1 cells show higher cell proliferation on the membranes (PVDF and P(VDF-TrFE)) with higher pore size $(\sim 1,5 \mu \mathrm{m})$ compared to the $\mathrm{P}(\mathrm{VDF}-\mathrm{HFP})$ membranes of lower pore size $(\sim 0,5 \mu \mathrm{m})$. C2C12 myoblast cell growth on porous membranes has never been studied prior to this study. In the present case, $\mathrm{C} 2 \mathrm{C} 12$ cells show higher proliferation on the membranes (PVDF) with higher pore size $(\sim 1,5 \mu \mathrm{m})$ and lowest degree of porosity $(\sim 20 \%)$.

As previously mentioned, scaffold design is an important parameter as it allows the control of cell morphology.
Previous studies with $\mathrm{C} 2 \mathrm{C} 12$ cells [31] demonstrated that the cells can adopt different morphologies on PVDF fibers compared to PVDF films. It was also observed that PVDF oriented fibers guide cell alignment and induce the elongation of these cells, which is not observed with randomly oriented fibers [31]. Hence, this study is important because, to our knowledge, the influence of PVDF porous membranes on myoblast C2C12 and MC3T3-E1 osteoblasts proliferation has not been reported.

The morphology of cells on the different porous membranes was analyzed by SEM and representative scanning electron micrographs are shown in Fig. 7.

Fig. 7 shows the cell morphology of $\mathrm{C} 2 \mathrm{C} 12$ cells after 1 day of culture on the different porous membranes. Comparing the samples, $\mathrm{C} 2 \mathrm{C} 12$ cells seem to maintain random arrangement on all membranes, but their morphology seems to vary, being more elongated on $\mathrm{P}$ (VDF-TrFE) substrates. Skeletal muscle is a highly organized tissue established by long parallel bundles of multinucleated myotubes, and cell alignment plays a key role on the skeletal muscle tissue engineering [31]. In this way, the P(VDF-TrFE) membranes may be a new approach for muscle tissue engineering once they induce cell elongation, which can be related to the overall higher pore size and degree of porosity. 
In previous studies [31], the influence of the polarization and morphology of PVDF films and fibers on the adhesion and morphology of myoblast cells was addressed. It was verified that both material topography and surface charge strongly influences cell adhesion and proliferation, but also that the cell morphology was influenced by the surface material. The cells adopt different morphologies when they are cultured on films or fiber substrates, surface morphology modification representing, therefore, a powerful tool to tailor cell development in tissue engineering approaches. The cells cultured on PVDF films show an irregular morphology and random arrangement, while elongated morphology along the direction of the oriented PVDF fibers was verified when cultured on fiber membranes [31]. Thus, the polymer microstructure shows play an important role in the cell adhesion and morphology, once the cells are highly sensitive to their surrounding [42]. In relation to the membranes used in this work, as mentioned above, C2C12 cells maintain, as verified in PVDF films, a random arrangement on all membranes, independently of the different microstructures. On the other hand, the $\mathrm{P}(\mathrm{VDF}-\mathrm{TrFE})$ substrates, with higher pore seize and degree of porosity seem to induce larger cell elongation.

The same behaviour was also observed for MC3T3-E1 cells (data not shown). It was also reported that macroporous membranes can influence the morphology of MC3T3-E1 cells, changing their square shape when cultured on non-porous membranes to elongated shape [43]. Contrary to what was observed with the myoblast cells, the P(VDF-TrFE) membranes will not be the most suitable for bone tissue engineering since these membranes promote a more elongated cell morphology. Hence, the morphology of P(VDF-TrFE) membranes imposes limitations on the formation of the focal adhesion. It is noticeable that the observed behavior is fully attributed to sample morphology and hydrophobicity variations, due to the similar electroactive phase content.

\section{Conclusions}

Porous electroactive membranes of poly(vinylidene fluoride) (PVDF) and its main copolymers - poly(vinylidene fluoride-co-hexafluoropropene), P(VDF-HFP), and poly(vinylidene fluoride-co-trifluoroethylene), P(VDF-TrFE), were evaluated as suitable membranes for tissue engineering applications. All samples show similar electroactive phase contents close to 90\%, although large differences are detected in the degree of crystallinity, ranging from $\sim 55 \%$ in the pure polymer to $\sim 35 \%$ in the PVDF-TrFE co-polymer. The main differences observed relate to the microstructure, ranging from the lowest degree of porosity and sizes in PVDF to the larger degree of porosity and pore size of $\mathrm{P}(\mathrm{VDF}-\mathrm{TrFE})$. It is found that cell morphology influences cell behavior. On the one hand, higher cell proliferation is found in the PVDF membranes with lower porosity and pore size and lower proliferation is found in the P(VDF-HFP) one. On the other hand, P(VDFTrFE) membranes, with the larger porosity and average pore size has distinct influence on both cell types, as the substrate leads to cell elongation which is preferred by the myoblast $\mathrm{C} 2 \mathrm{C} 12$ cells.

\section{Acknowledgements}

This work is funded by FEDER funds through the "Programa Operacional Fatores de Competitividade COMPETE" and by national funds arranged by FCTFundação para a Ciência e a Tecnologia, project references PTDC/CTM-NAN/112574/2009 and PEST-C/FIS/UI607/2014. The authors also thank funding from "Matepro -Optimizing Materials and Processes", ref. NORTE-070124-FEDER-000037", co-funded by the "Programa Operacional Regional do Norte" (ON.2 - O Novo Norte), under the "Quadro de Referência Estratégico Nacional" (QREN), through the "Fundo Europeu de Desenvolvimento Regional" (FEDER). CR thanks the FCT for the SFRH/BPD/ 90870/2012 grant.

\section{References}

[1] M.E. Gomes, R.L. Reis, Tissue engineering: key elements and some trends, Macromol. Biosci. 4 (2004) 737-742.

[2] G. Chen, T. Ushida, T. Tateishi, Scaffold design for tissue engineering, Macromol. Chem. Phys. 203 (2002) 67-77.

[3] M.S. Shoichet, Polymer scaffolds for biomaterials applications, Macromolecules 43 (2010) 581-591.

[4] C. Liu, Z. Xia, J.T. Czernuszka, Design and development of threedimensional scaffolds for tissue engineering, Chem. Eng. Res. Des. 85 (2007) 1051-1064.

[5] F.J. O'Brien, Biomaterials \& scaffolds for tissue engineering, Mater. Today 14 (2011) 88-95.

[6] B. Dhandayuthapani, Y. Yoshida, T. Maekawa, D.S. Kumar, Polymeric scaffolds in tissue engineering application: a review, Int. J. Polym. Sci. 2011 (2011), http://dx.doi.org/10.1155/2011/290602.

[7] M.N. Rahaman, J.J. Mao, Stem cell-based composite tissue constructs for regenerative medicine, Biotechnol. Bioeng. 91 (2005) 261-284.

[8] D. Howard, L.D. Buttery, K.M. Shakesheff, S.J. Roberts, Tissue engineering: strategies, stem cells and scaffolds, J. Anat. 213 (2008) $66-72$.

[9] B.P. Chan, K.W. Leong, Scaffolding in tissue engineering: general approaches and tissue-specific considerations, Eur. Spine J. 17 (2008) S467-S479.

[10] Q.L. Loh, C. Choong, Three-dimensional scaffolds for tissue engineering applications: role of porosity and pore size, Tissue Eng. Part B Rev. 19 (2013) 485-502.

[11] F.J. O'Brien, B.A. Harley, I.V. Yannas, L.J. Gibson, The effect of pore size on cell adhesion in collagen-GAG scaffolds, Biomaterials 26 (2005) 433-441.

[12] S. Nehrer, H.A. Breinan, A. Ramappa, G. Young, S. Shortkroff, L.K. Louie, C.B. Sledge, I.V. Yannas, M. Spector, Matrix collagen type and pore size influence behaviour of seeded canine chondrocytes, Biomaterials 18 (1997) 769-776.

[13] B.D. Ratner, A.S. Hoffman, F.J. Schoen, J.E. Lemons, Biomaterials Science: An Introduction to Materials in Medicine, Elsevier Science, 2012.

[14] P. Martins, A.C. Lopes, S. Lanceros-Mendez, Electroactive phases of poly(vinylidene fluoride): determination, processing and applications, Prog. Polym. Sci. 39 (2014) 683-706.

[15] W. Ma, H. Yuan, X. Wang, The effect of chain structures on the crystallization behavior and membrane formation of poly(vinylidene fluoride) copolymers, Membranes 4 (2014) 243-256.

[16] H. Chen, Y. Liu, Z. Jiang, W. Chen, Y. Yu, Q. Hu, Cell-scaffold inter action within engineered tissue, Exp. Cell Res. 323 (2014) 346-351.

[17] R. Balint, N.J. Cassidy, S.H. Cartmell, Electrical stimulation: a novel tool for tissue engineering, Tissue Eng. Part B Rev. 19 (2013) 48-57.

[18] D.McK. Ciombor, R.K. Aaron, Influence of electromagnetic fields on endochondral bone formation, J. Cell. Biochem. 52 (1993) 37-41.

[19] M.P. Prabhakaran, L. Ghasemi-Mobarakeh, G. Jin, S. Ramakrishna, Electrospun conducting polymer nanofibers and electrical stimulation of nerve stem cells, J. Biosci. Bioeng. 112 (2011) 501-507.

[20] Y.C. Chan, S. Ting, Y.K. Lee, K.M. Ng, J. Zhang, Z. Chen, C.W. Siu, S.K.W. Oh, H.F. Tse, Electrical stimulation promotes maturation of cardiomyocytes derived from human embryonic stem cells, J. Cardiovasc. Transl. Res. 6 (2013) 989-999.

[21] E. Yamada, S. Hashimoto, K. Tachibana, M. Okada, K. Yamasaki, H. Kondo, K. Imoto, S. Mochizuki, T. Fujisato, M. Ohsuga, H. Otani, 
Effect of electric stimulation on adhesion and proliferation of cultured muscle cells, in: Proc. 12th World Multi-Conference on Systemics Cybernetics and Informatics, 2, 2008, pp. 124-129.

[22] C.M. Murphy, M.G. Haugh, F.J. O'Brien, The effect of mean pore size on cell attachment, proliferation and migration in collagenglycosaminoglycan scaffolds for bone tissue engineering, Biomaterials 31 (2010) 461-466.

[23] W. Wang, B. Cao, L. Cui, J. Cai, J. Yin, Adipose tissue engineering with human adipose tissue-derived adult stem cells and a novel porous scaffold, J. Biomed. Mater. Res. B Appl. Biomater. 101 B (2013) $68-75$.

[24] S. Rajabi-Zeleti, S. Jalili-Firoozinezhad, M. Azarnia, F. Khayyatan, S. Vahdat, S. Nikeghbalian, A. Khademhosseini, H. Baharvand, N. Aghdami, The behavior of cardiac progenitor cells on macroporous pericardium-derived scaffolds, Biomaterials 35 (2014) 970-982.

[25] X.H. Wang, S. Shi, G. Guo, S.Z. Fu, M. Fan, F. Luo, X. Zhao, Y.Q. Wei, Z.Y. Qian, Preparation and characterization of a porous scaffold based on poly(D,L-lactide) and N-hydroxyapatite by phase separation, J. Biomater. Sci. Polym. Ed. 22 (2011) 1917-1929.

[26] P. Gentile, V. Chiono, C. Tonda-Turo, A.M. Ferreira, G. Ciardelli, Polymeric membranes for guided bone regeneration, Biotechnol. J. 6 (2011) 1187-1197.

[27] R. James, R.K. Nagarale, V.K. Sachan, C. Badalucco, P.K. Bhattacharya, S.G. Kumbar, Synthesis and characterization of electrically conducting polymers for regenerative engineering applications: sulfonated ionic membranes, Polym. Advan. Technol. 25 (2014) $1439-1445$.

[28] D.C. Bassett, Developments in crystalline polymers, J. Polym. Sci. Polym. Lett. Ed. 20 (1982) 559-560.

[29] S. Lanceros-Méndez, J.F. Mano, A.M. Costa, V.H. Schmidt, FTIR AND DSC studies of mechanically deformed $\beta$-PVDF films, J. Macromol. Sci. B 40 (2001) 517-527.

[30] C. Ribeiro, S. Moreira, V. Correia, V. Sencadas, J.G. Rocha, F.M. Gama, J.L.G. Ribelles, S. Lanceros-Mendez, Enhanced proliferation of preosteoblastic cells by dynamic piezoelectric stimulation, RSC Adv. 2 (2012) 11504-11509.

[31] P.M. Martins, S. Ribeiro, C. Ribeiro, V. Sencadas, A.C. Gomes, F.M. Gama, S. Lanceros-Méndez, Effect of poling state and morphology of piezoelectric poly(vinylidene fluoride) membranes for skeletal muscle tissue engineering, Rsc Adv. 3 (2013) $17938-17944$.

[32] R. Magalhães, N. Durães, M. Silva, J. Silva, V. Sencadas, G. Botelho, J.L. Gómez Ribelles, S. Lanceros-Méndez, The role of solvent evaporation in the microstructure of electroactive $\beta$-poly(vinylidene fluoride) membranes obtained by isothermal crystallization, Soft Mater. 9 (2010) 1-14.

[33] A. California, V.F. Cardoso, C.M. Costa, V. Sencadas, G. Botelho, J.L. Gómez-Ribelles, S. Lanceros-Mendez, Tailoring porous structure of ferroelectric poly(vinylidene fluoride-trifluoroethylene) by controlling solvent/polymer ratio and solvent evaporation rate, Eur. Polym. J. 47 (2011) 2442-2450.

[34] A. Ferreira, J. Silva, V. Sencadas, J.L.G. Ribelles, S. Lanceros-Méndez, Poly[(vinylidene fluoride)-co-trifluoroethylene] membranes obtained by isothermal crystallization from solution, Macromol. Mater. Eng. 295 (2010) 523-528.

[35] D.-J. Lin, C.-L. Chang, F.-M. Huang, L.-P. Cheng, Effect of salt additive on the formation of microporous poly(vinylidene fluoride) membranes by phase inversion from LiClO4/Water/DMF/PVDF system, Polymer 44 (2003) 413-422.

[36] Y. Su, C. Chen, Y. Li, J. Li, PVDF Membrane formation via thermally induced phase separation, J. Macromol. Sci. A 44 (2007) 99-104.

[37] M. Gryta, M. Barancewicz, Influence of morphology of PVDF capillary membranes on the performance of direct contact membrane distillation, J. Memb. Sci. 358 (2010) 158-167.

[38] L. Shi, R. Wang, Y. Cao, C. Feng, D.T. Liang, J.H. Tay, Fabrication of poly(vinylidene fluoride-co-hexafluropropylene) (PVDF-HFP) asymmetric microporous hollow fiber membranes, J. Memb. Sci. 305 (2007) 215-225.

[39] A.A. Prabu, J.S. Lee, K.J. Kim, H.S. Lee, Infrared spectroscopic studies on crystallization and Curie transition behavior of ultrathin films of P(VDF/TrFE) (72/28), Vib. Spectrosc. 41 (2006) 1-13.

[40] N. Ataollahi, A. Ahmad, H. Hamzah, M. Rahman, N. Mohamed, Preparation and characterization of PVDF-HFP/MG49 based polymer blend electrolyte, Int. J. Electrochem. Sci. 7 (2012) 6693-6703.

[41] C. Ribeiro, J.A. Panadero, V. Sencadas, S. Lanceros-Mendez, M.N. Tamano, D. Moratal, M. Salmeron-Sanchez, J.L. Gomez Ribelles, Fibronectin adsorption and cell response on electroactive poly(vinylidene fluoride) films, Biomed. Mater. 7 (2012) 035004.

[42] C. Ribeiro, D.M. Correia, S. Ribeiro, V. Sencadas, G. Botelho, S. Lanceros-Méndez, Piezoelectric poly(vinylidene fluoride) microstructure and poling state in active tissue engineering, Eng. Life Sci. (2015), http://dx.doi.org/10.1002/elsc.201400144.

[43] T. Orita, M. Tomita, K. Kato, Regulation of cellular responses to macroporous inorganic films prepared by the inverse-opal method, Colloids Surf. B 84 (2011) 187-197. 